\title{
Highly Efficient Synthesis of an Emerging Lipophilic Antioxidant: 2-Ethylhexyl Ferulate
}

\author{
Kuo-Chuan Huang ${ }^{1}$, Ying $\mathrm{Li}^{2}$, Chia-Hung Kuo ${ }^{3}$, Yawo-Kuo Twu ${ }^{1}$ and Chwen-Jen Shieh ${ }^{2, *}$ \\ 1 Department of BioIndustry Technology, Da-Yeh University, 168 University Road, Dacun, Changhua 51591, \\ Taiwan; freedomlove0216@gmail.com (K.-C.H.); poly2001@mail.dyu.edu.tw (Y.-K.T.) \\ 2 Biotechnology Center, National Chung Hsing University, 250 Kuokuang Road, Taichung 40227, Taiwan; \\ quatrefoil47@yahoo.com.tw \\ 3 Department of Seafood Science, National Kaohsiung Marine University, 142 Haijhuan Road, Nanzih District, \\ Kaohsiung 81157, Taiwan; chkuo@webmail.nkmu.edu.tw \\ * Correspondence: cjshieh@nchu.edu.tw; Tel.: +886-4-2284-0450 (ext. 5121); Fax: +886-4-2286-1905
}

Academic Editors: Jean-Marc Sabatier and Derek J. McPhee

Received: 7 March 2016; Accepted: 7 April 2016; Published: 12 April 2016

\begin{abstract}
Ferulic acid in ester form has shown a stronger ability in ameliorating certain pathological conditions and inhibiting lipid oxidation. In present study, a solvent-free and reduced pressure evaporation system was developed for lipase-catalyzed synthesis of 2-ethylhexyl ferulate (2-EF) from ferulic acid and 2-ethylhexanol. A Box-Behnken design with response surface methodology (RSM) and artificial neural network (ANN) was selected to model and optimize the process. Based on the yields of 2-EF, reaction temperature was shown to be the most important process factor on the molar conversion among all variables. The residual values and the coefficient of determination $\left(R^{2}\right)$ calculated from the design data indicated that ANN was better than RSM in data fitting. Overall, the present lipase-catalyzed approach for 2-EF synthesis at low reaction temperature in a reduced pressure evaporation system shows high 2-EF production efficiency. Notably, this approach can reduce the enzyme denaturation and ferulic acid oxidation that usually occur during long-term biosynthetic operations at high temperature.
\end{abstract}

Keywords: 2-ethylhexyl ferulate; lipase; reduced pressure evaporation system; response surface methodology; artificial neural network

\section{Introduction}

Ferulic acid (FA) belongs to the family of phenolic acids and is very abundant in grains, fruits and vegetables. Studies have shown that FA displays excellent antioxidant [1], ultraviolet-absorbing activities [2,3] and potential health benefits against cardiovascular problems, inflammatory diseases and cancer [4]. However, the solubility of FA in hydrophobic solvents is low, thus limiting its utilization in the pharmaceutical, cosmetic and food industries. In order to increase utilization of FA, lipophilization is needed, where enzymatic esterification with alcohols has proved to be a promising approach [5-8]. In recent years, many studies have report that the enzymatic synthesis of hydrophobic derivatives of FA can increase its oil-solubility [9-11], and some of them have been applied for preparation of emulsion-based creams due to their anti-inflammatory activity [12]. FA esters, the hydrophobic derivatives of FA, have also demonstrated other bioactivities such as antioxidant [13], anticonvulsant [14], synergistic photobactericidal effects [15], and antithrombotic activities [16], as well as inhibition of the atherogenic effects of leptin [17]. Interestingly, FA esters possess better inhibitory effect on lipid oxidation than FA [18].

Enzymatic biosynthesis of these compounds has attracted much attention in recent years, and it may be a better approach in comparison to conventional chemical processes [19-23]. It has been 
reported that continuous synthesis of alkyl ferulate by immobilized lipase shows great conversion rates (approximately $90 \%$ ) at $90^{\circ} \mathrm{C}$ after two days [21]. It should be kept in mind that FA is susceptible to oxidation under high temperatures. Novozym ${ }^{\circledR} 435$ had been used in the lipase-catalyzed synthesis of ferulate esters, but the yield was only $17 \%$ after several days [22]. Generally, solvent-free reaction systems are applied in the lipase-catalyzed synthesis of ferulate esters to decrease the reaction time and increase the yield [20,23]. The solvent-free system is a simple mixture of substrates, offering advantages including maximization of substrate concentration, greater volumetric production, and cost savings in reactor design and product separation. In addition, the boiling point of the component liquids is lower in a reduced pressure evaporation system than that in the atmosphere at the same temperature, suggesting that the byproducts with relative low vapor pressure physical characteristics are more prone to be eliminated in the reduced pressure system. This may increase the efficiency of the lipase-catalyzed reaction. Therefore, a reduced pressure evaporation system combined with a solvent-free system may be an excellent strategy to overcome the problems of long reaction time and low yields of FA esters synthesis. So far, the literature regarding the lipase-catalyzed esterification of ferulic acid in a reduced pressure evaporation system is still limited. Notably, there have been no reports regarding lipase-catalyzed synthesis of 2-ethylhexylferulate (2-EF), a common FA ester with great inhibitory effect on lipid oxidation, which has been widely used as the antioxidant in the food and cosmetic industries.

Recently, response surface methodology (RSM) and an artificial neural network (ANN) approach have been applied for optimization and process modeling. The development of an optimum enzymatic synthesis procedure to improve the yield conversion to reduce production costs would be attractive for manufacturers and consumers. RSM and ANN have been successfully applied to model and optimize extraction of lignans [24], curdlan production [25], and biodiesel production [26]. In this study, a reduced pressure evaporation system was used to synthesize 2-ethylhexyl ferulate (2-EF) under solvent free conditions. RSM and ANN were employed to investigate the effects of different reaction variables (reaction time, reaction temperature, and enzyme amount) on the response (yield \%), and to obtain the optimal conditions to solve the problems of long reaction time and low yield of FA esters.

\section{Results and Discussion}

The present study applied RSM and ANN for experimental design of enzymatic synthesis of 2-EF in a solvent-free system. The molar ratio of FA and 2-ethylhexanol (the reactants) was 1:129, and the independent parameters selected for the experimental design were: reaction time $\left(\mathrm{X}_{1}\right)$, enzyme amount $\left(X_{2}\right)$, and reaction temperature $\left(X_{3}\right)$. Their ranges and levels are given in Table 1.

\subsection{RSM Model}

The RSM Box-Behnken procedure was employed to fit the second-order polynomial equation to the experimental data (Table 1). Among the various treatments, the highest molar conversion $(98.9 \% \pm 2.5 \%)$ was observed in treatment 12 (reaction temperature of $80{ }^{\circ} \mathrm{C}$, enzyme amount of 1500 PLU and reaction time of $16 \mathrm{~h})$, and the lowest molar conversion $(42.7 \% \pm 3.3 \%)$ was observed in treatment 10 (reaction temperature of $60{ }^{\circ} \mathrm{C}$, enzyme amount of 1000 PLU and reaction time of $8 \mathrm{~h}$ ). The second-order polynomial equation obtained was as follows:

$$
\begin{aligned}
& Y=-968.26667+3.60052 X_{1}+26.28208 X_{2}+0.039783 X_{3}-0.027812 X_{1} X_{2}+0.0003 X_{1} X_{3}+0.0004 X_{2} X_{3} \\
& -0.028971 X_{1}{ }^{2}-0.17154 X_{2}{ }^{2}-0.0000305167 X_{3}{ }^{2}
\end{aligned}
$$

The analysis of variance (ANOVA), represented in Table 2, indicates that this second-order polynomial model was highly significant and adequate to represent the actual relationship between the response (molar conversion) and the significant variables with a very small $p$ value $(<0.001)$ and a satisfactory coefficient of determination $\left(R^{2}=0.9852\right)$. The ANOVA results of responses reveal an insignificant "lack of fit" for $p>0.05$. Therefore, these models were adequate for prediction within the range of variables employed. Furthermore, the ANOVA results indicate that the linear term of 
$X_{1}$ and $X_{3}$ and the square term of $X_{2}^{2}$ and $X_{3}^{2}$ had significant $(p<0.05)$ influence on molar conversion. The interaction terms had less influence $(p>0.05)$.

Table 1. Box-Behnken design and observed experimental data for 3-level-3-factor response surface analysis.

\begin{tabular}{ccccc}
\hline \multirow{2}{*}{ Treatment No. $^{\mathbf{a}}$} & \multicolumn{3}{c}{ Experimental Variables } & \multirow{2}{*}{ Observed Molar Conversion (\%) } \\
\cline { 2 - 4 } & $\mathbf{X}_{\mathbf{1}} \mathbf{( h )}$ & $\mathbf{X}_{\mathbf{2}} \mathbf{( P L U )}$ & $\left.\mathbf{X}_{\mathbf{3}} \mathbf{(}^{\circ} \mathbf{C}\right)$ & \\
\hline 1 & 16 & 500 & 80 & $85.7 \pm 3.4$ \\
2 & 16 & 1000 & 70 & $92.4 \pm 3.1$ \\
3 & 16 & 1000 & 70 & $92.0 \pm 2.8$ \\
4 & 16 & 1000 & 70 & $91.7 \pm 2.3$ \\
5 & 8 & 500 & 70 & $68.7 \pm 4.1$ \\
6 & 24 & 500 & 70 & $82.3 \pm 3.2$ \\
7 & 8 & 1500 & 70 & $80.4 \pm 2.1$ \\
8 & 24 & 1500 & 70 & $98.8 \pm 1.6$ \\
9 & 16 & 500 & 60 & $39.8 \pm 2.7$ \\
10 & 8 & 1000 & 60 & $42.7 \pm 3.3$ \\
11 & 16 & 1500 & 60 & $94.8 \pm 4.2$ \\
12 & 16 & 1500 & 80 & $64.2 \pm 2.5$ \\
13 & 24 & 1000 & 60 & $86.3 \pm 2.8$ \\
14 & 8 & 1000 & 80 & $98.7 \pm 1.9$ \\
15 & 24 & 1000 & 80 &
\end{tabular}

Table 2. ANOVA for synthetic variables pertaining to response percent molar conversion.

\begin{tabular}{cccc}
\hline Source & Sum of Squares & Degree of Freedom & Prob $>$ F $^{\mathbf{a}}$ \\
\hline Model & 22.50 & 9 & 0.0005 \\
Linear & & & \\
$\mathrm{X}_{1}$ & 1.87 & 1 & 0.0033 \\
$\mathrm{X}_{2}$ & 0.85 & 1 & 0.0614 \\
$\mathrm{X}_{3}$ & 14.72 & 1 & $<0.0001$ \\
Interaction & & & \\
$\mathrm{X}_{1} \mathrm{X}_{2}$ & 0.01 & 1 & 0.7297 \\
$\mathrm{X}_{1} \mathrm{X}_{3}$ & 0.17 & 1 & 0.1762 \\
$\mathrm{X}_{2} \mathrm{X}_{3}$ & 0.02 & 1 & 0.5973 \\
Square $_{\mathrm{X}_{1}{ }^{2}}$ & 0.02 & 1 & \\
$\mathrm{X}_{2}{ }^{2}$ & 0.79 & 1 & 0.6545 \\
$\mathrm{X}_{3}{ }^{2}$ & 4.33 & 1 & 0.0188 \\
Lack of fit & 15.20 & 3 & 0.0005 \\
Pure error & 0.99 & 2 & 0.09 \\
Total error & 16.19 & 5 & \\
\hline & a Prob $>$ F: level of significance. & \\
\hline
\end{tabular}

The effect of varying reaction temperature and enzyme amount on transesterification efficiency at a constant reaction time of $16 \mathrm{~h}$ was shown in Figure $1 \mathrm{~A}$. With the lowest reaction temperature $\left(60{ }^{\circ} \mathrm{C}\right)$ and enzyme amount (500 PLU), a 2-EF molar conversion of $39.8 \%$ was obtained. Low molar conversions are also found in a previous report on lipase-catalyzed synthesis of ferulate esters at the temperature of $60^{\circ} \mathrm{C}$, enzyme amount of $100 \mathrm{mg}$, and time of $240 \mathrm{~h}$ [22]. The low molar conversion of ferulate esters can be improved by using a reduced pressure evaporation system. In the reduced pressure evaporation system, when the enzyme amount was increased to 1500 PLU and the reaction temperature was increased to $80^{\circ} \mathrm{C}$, the molar conversion of 2-EF was increased to 98.9 (Figure 1A). The great increase in molar conversion can result from the impact of solvent-free and reduced pressure evaporation system which increases the reaction rate of lipase-catalyzed biosynthesis by elevating the 
substrate concentration and eliminating byproducts with low vapor pressure physical characteristics. Figure 1B shows the effects of reaction time and reaction temperature on 2-EF biosynthesis at a constant enzyme amount (1000 PLU). At the lowest reaction time $(8 \mathrm{~h})$ and reaction temperature $\left(60{ }^{\circ} \mathrm{C}\right)$, the molar conversion was $42.7 \% \pm 3.3 \%$. Figure $1 \mathrm{C}$ shows the effects of reaction time and enzyme amount on 2-EF biosynthesis at a constant reaction temperature. In this regard, enzyme amount had an insignificant effect on molar conversion, while reaction time had only a partial effect on molar conversion. Taken together, the molar conversion significantly increased when the reaction temperature and reaction time increased. As the ANOVA results shown in Table 2 indicate, reaction temperature and reaction time are important factors in Novozym ${ }^{\circledR} 435$-catalyzed reactions, which is in accordance with our previous works [27]. However, it has been reported that higher reaction temperature might decrease the lipase activity [21]. Thus, a reduced pressure evaporation system can be a good solution for lipase-catalyzed synthesis of FA esters in order to obtain a higher conversion at a lower reaction temperature.

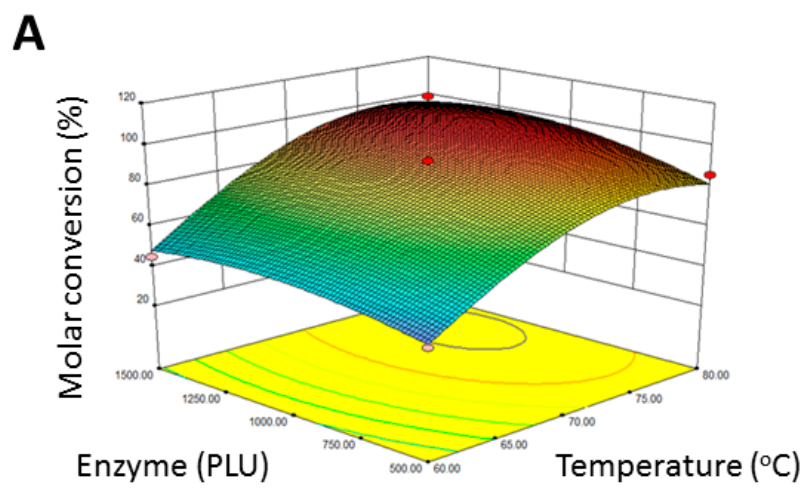

B

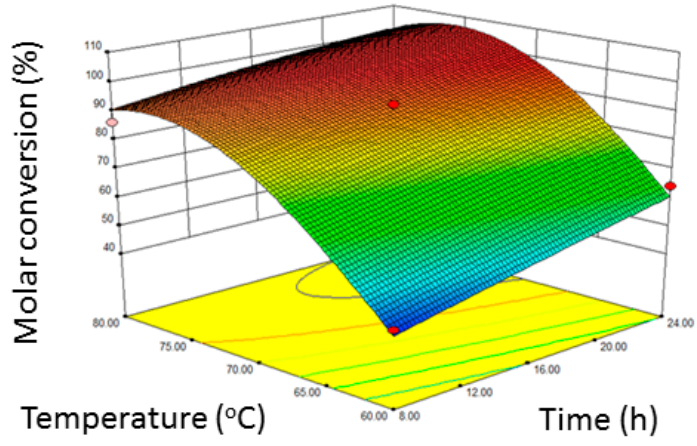

C

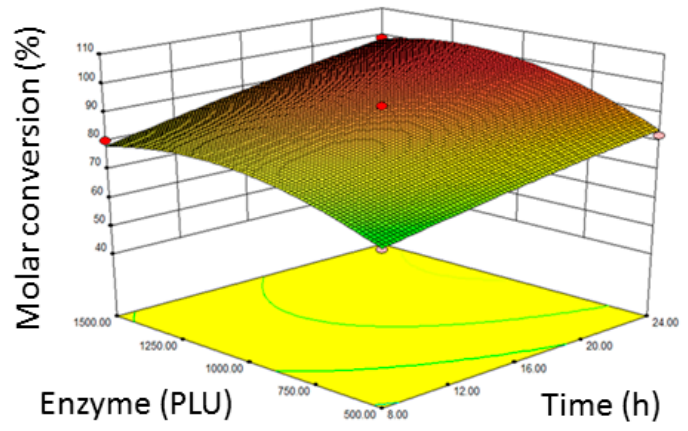

Figure 1. Response surface plot for the relationships between molar conversion and experimental variables. Response surface plot showing the relationships between molar conversion of 2-ethylhexyl ferulate and reaction parameters: (A) reaction temperature and enzyme amount; (B) reaction temperature and reaction time and $(\mathbf{C})$ reaction time and enzyme amount.

\subsection{ANN Model}

ANN is a promising modeling methodology for non-linear multivariate process/reaction [28]. In this study, the data generated from the Box-Behnken design (Table 1) were employed to generate an ANN model for the enzymatic 2-EF synthesis. The proposed ANN consisted of three layers in the present work: an input layer with four neurons (reaction time, reaction temperature, and enzyme amount), a hidden layer with several neurons and an output layer containing one output neuron (molar conversion). The feed-forward neural network was trained by using incremental back propagation (IBP), batch backpropagation (BBP) and Levenberg-Marquardt algorithm (LM) or genetic algorithm (GA), respectively. All neurons from the hidden layer and output layer were calculated by a sigmoid transfer function. Different numbers of neurons, from three to six, 
were examined. The various architectures for ANN models were developed using NeuralPower software (Version 2.5, CPC-X Software, USA; available from Internet: http:/ / www.brothersoft.com/ neuralpower-download-21356.html), and the best one was selected based on the maximization of the $R^{2}$ value and the minimization of the RMSE value.

All results from the test were evaluated statistically based on the RMSE values. According to Figure 2, the best performance network was trained using a LM algorithm with a sigmoid transfer function, which exhibited a lower and stable RMSE. It is noted that the curve of the RMSE levels off at five hidden neurons. Therefore, the best ANN model in this study is determined to be a multilayer feed forward connection, trained by a LM algorithm using a sigmoid transfer function that consists of a 3-6-1 topology, as shown in Figure 3. This learning was acquired with $\mathrm{RMSE}=0.79, R^{2}=0.99$.

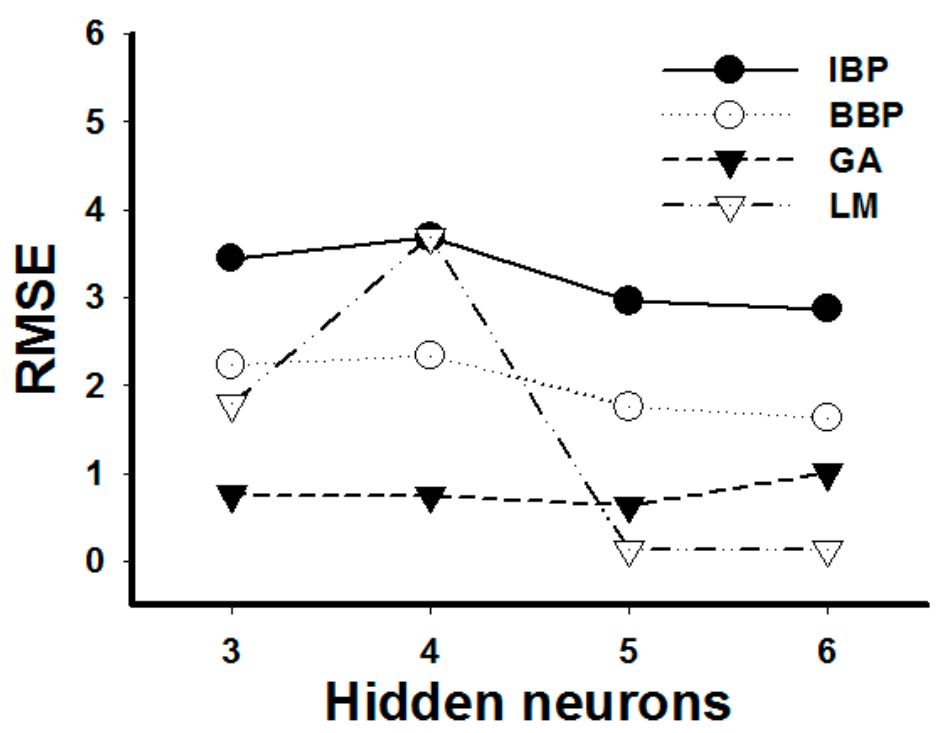

Figure 2. Learning curves of ANN model at different hidden neurons. The training set uses sigmoid transfer function in the hidden layer and output layer based on increment back propagation (IBP), batch back propagation (BBP), Levenberg-Marquardt algorithm (LM) or genetic algorithm (GA).

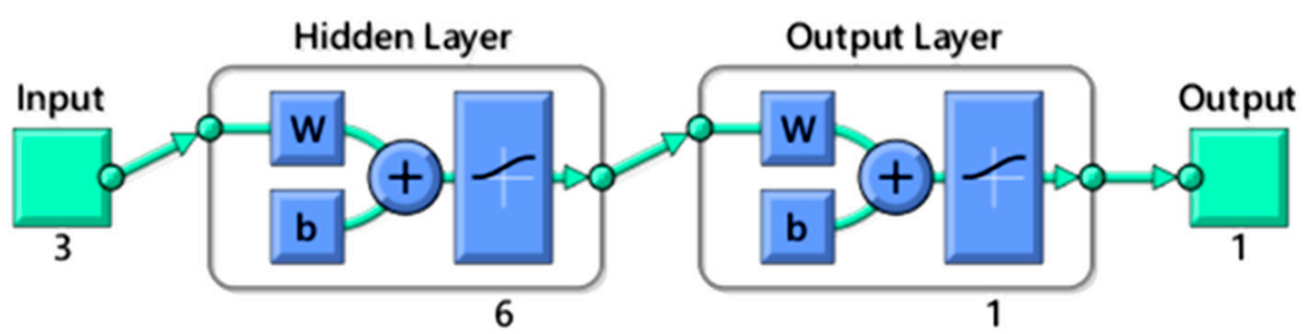

Figure 3. The optimal architecture of multilayer feed forward neural network. The network contains three inputs (reaction temperature, reaction time and enzyme amount), one hidden layer with six nodes and one output (molar conversion of 2-ethylhexyl ferulate). W means weight; b means basic input/output system (BIOS).

According to Figure 4, the reaction time and reaction temperature displayed great impact on the conversion with a relative importance of approximate $39 \%$ and $46 \%$, respectively. These results are in accordance with the ones obtained with RSM. 


\section{A: time B: enzyme C: temperature}

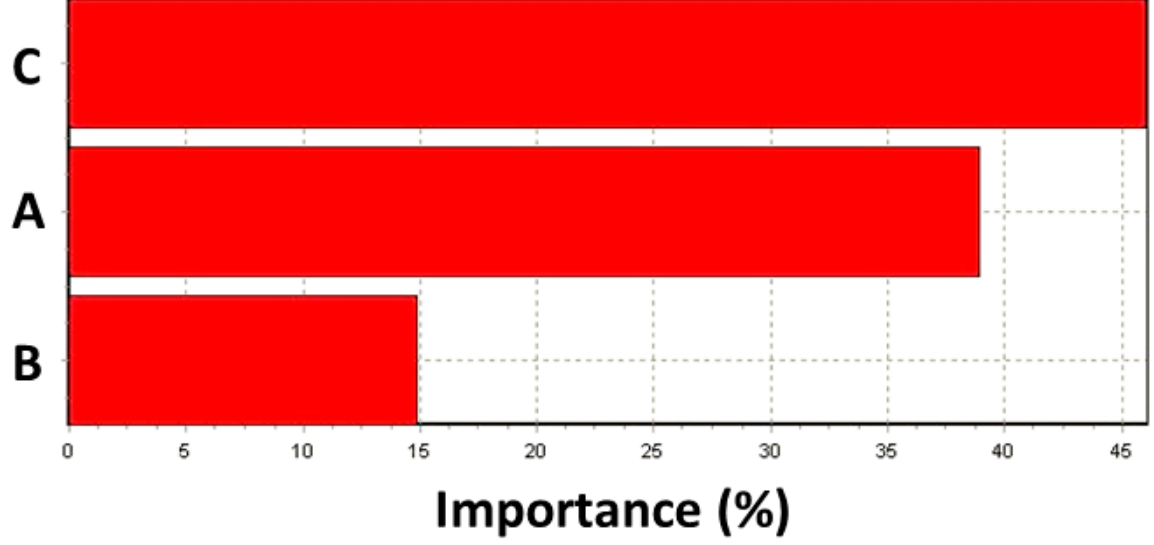

Figure 4. Importance of experimental variables on lipase-catalyzed synthesis of 2-ethylhexyl ferulate.

\subsection{Comparison between RSM and ANN and Optimization for Experimental Condition}

The distribution of the residual values obtained from the experimental data of Box-Behnken design experiments minus the related computed RSM and ANN data are shown in Figure 5. It was observed that the deviations of residual values showed a relatively small variation in the ANN model when compared with the RSM model. This suggested that ANN was better than RSM in data fitting.

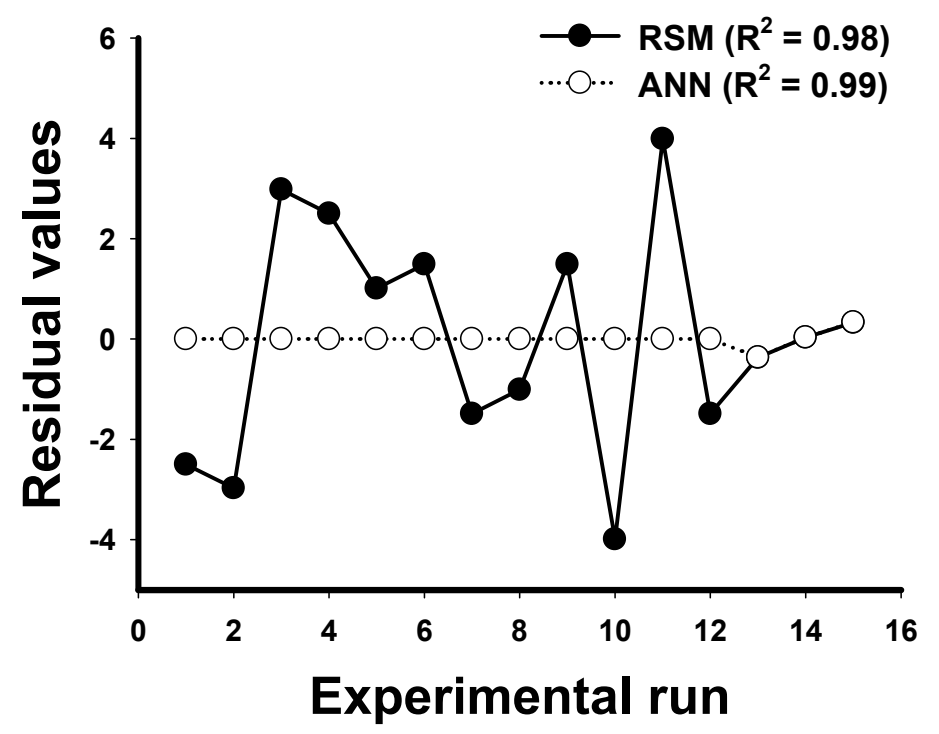

Figure 5. The distribution of residual values for each experimental run of Box-Behnken design experiments employing the RSM and ANN models. Coefficient of determination $\left(R^{2}\right)$ calculated from the design data for RSM and ANN models were 0.98 and 0.99, respectively. Residual values: predicted values minus actual values.

In order to validate and test the extrapolative capability of both the ANN and RSM models, a completely new set of five experiments was conducted on an experimental range which does not belong to the design data sets. The experimental and predicted values of the response for both the ANN and RSM models are given in Table 3. The performance of the newly constructed ANN and RSM models were statistically measured, in terms of AAD and RMSE values. The RMSEs for RSM and ANN were found as 7.322 and 5.152. These results indicate that the RSM prediction has a greater deviation than the ANN prediction. The AAD for RSM and ANN was found to be 10.046 and 9.430. From the results, it was observed that predictive power of ANN was found to be more powerful than RSM. 
Table 3. Validation and comparison of RSM- and ANN-modeling biocatalysis.

\begin{tabular}{ccccccc}
\hline \multirow{2}{*}{ Run } & \multicolumn{3}{c}{ Independent Variable } & \multicolumn{3}{c}{ Molar Conversion (\%) } \\
\cline { 2 - 7 } & $\mathbf{X}_{\mathbf{1}} \mathbf{( h )}$ & $\mathbf{X}_{\mathbf{2}} \mathbf{( P L U )}$ & $\left.\mathbf{X}_{\mathbf{3}} \mathbf{(}^{\circ} \mathbf{C}\right)$ & Experimental & RSM Predicted & ANN Predicted \\
\hline 1 & 14 & 1250 & 75 & 93.2 & 98.8 & 95.0 \\
2 & 15 & 750 & 65 & 76.8 & 71.2 & 73.5 \\
3 & 10 & 850 & 75 & 74.6 & 90 & 85.3 \\
4 & 9 & 1400 & 65 & 65.4 & 65.1 & 62.2 \\
5 & 20 & 950 & 60 & 51.7 & 56.9 & 56.3 \\
& & & & AAD & 10.046 & 9.430 \\
& & & & RMSE & 7.322 & 5.152 \\
\hline
\end{tabular}

Ridge max analysis can be used to determine optimum operating conditions by computing the estimated ridge of the maximum response for increasing the radius from the center of the original design. As shown in Table 4, the optimum condition for lipase-catalyzed synthesis of 2-EF determined by the ridge max analysis of RSM was reaction time of $23 \mathrm{~h}$, reaction temperature of $71{ }^{\circ} \mathrm{C}$ and enzyme amount of 1422 PLU. A verification experiment performed at this condition obtained a molar conversion of $99.43 \%$. Notably, higher molar conversion (99.74) was observed when the experiment was performed using the ANN-modeled optimal conditions (Table 4).

Table 4. The optimal trial obtained from RSM and ANN models.

\begin{tabular}{cccccc}
\hline \multirow{2}{*}{ Model } & \multicolumn{3}{c}{ Optimal Condition } & \multicolumn{2}{c}{ Relative Conversion (\%) } \\
\cline { 2 - 6 } & $\mathbf{X}_{\mathbf{1}} \mathbf{( h )}$ & $\mathbf{X}_{\mathbf{2}} \mathbf{( P L U )}$ & $\mathbf{X}_{\mathbf{3}}\left({ }^{\circ} \mathbf{C}\right)$ & Experimental Value & Predicted Value \\
\hline RSM & 23 & 1422 & 71 & 99.43 & 102.74 \\
ANN & 24 & 1485 & 78 & 99.74 & 99.82 \\
\hline
\end{tabular}

\subsection{Evaluation of Enzyme Reusability}

To examine the enzyme reusability, the ability of reused immobilized lipase for 2-EF synthesis was investigated under optimum conditions (Figure 6). After reaction, the mixture was filtered through a $0.45 \mu \mathrm{m}$ membrane. The immobilized lipase was then recovered from the membrane, washed three times with fresh reaction media and dried before reuse in the next batch. After the immobilized lipase was reused five times, the molar conversion of 2-EF still remained at about $90.4 \%$. This result showed that the immobilized lipase remained stable through long-term 2-EF exposure. Thus, the result demonstrated that the lipase could be effectively applied for 2-EF synthesis in the reduced pressure evaporation system and that the stability was high enough to permit reuse.

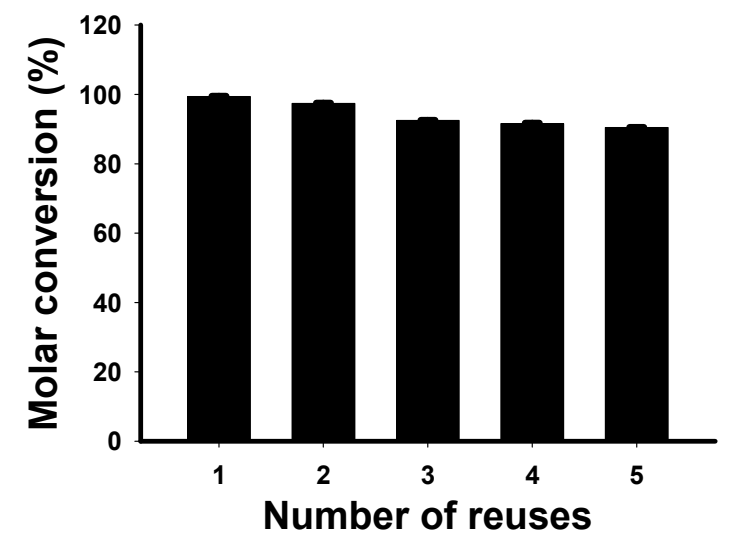

Figure 6. Reusability of Novozym ${ }^{\circledR} 435$ in the synthesis of 2-ethylhexyl ferulate performed under optimum conditions. 


\section{Experimental Section}

\subsection{Materials}

Immobilized lipase Novozym ${ }^{\circledR} 435$ (10,000 U/g; propyl laurate units (PLU)) from Candida antarctica B (EC3.1.1.3) supported on a macroporous acrylic resin was purchased from NovoNor disk Bioindustrials Inc. (Copenhagen, Denmark). Ferulic acid (FA), 2-ethylhexanol, 2-methyl-2-butanol, methanol and acetic acid were purchased from the Sigma Chemical Co. (St. Louis, MO, USA). A $4 \AA$ molecular sieve was purchased from Davison Chemical (Baltimore, MD, USA). 2-ethylhexyl ferulate (2-EF) was purchased from Shanghai Richem International Co., Ltd. (Shanghai, China). All the other reagents and chemicals, unless otherwise noted, were of analytical grade.

\subsection{Enzymatic 2-ethylhexyl Ferulate Synthesis}

FA was dissolved in 2-ethylhexanol $(1 \mathrm{~mL})$ to the concentration of $0.05 \mathrm{M}$ in the fingernails emissions glass flask that contained Novozym ${ }^{\circledR} 435$ of a rotary evaporator (EYELA N-1100, Tokyo Rikakikai Co., Ltd., Bohemia, NY, USA), which operated at $80 \mathrm{rpm}$ and 560 torr under different experimental conditions. The esterification of FA with 2-EF catalyzed by Novozym ${ }^{\circledR} 435$ is represented in Scheme 1.
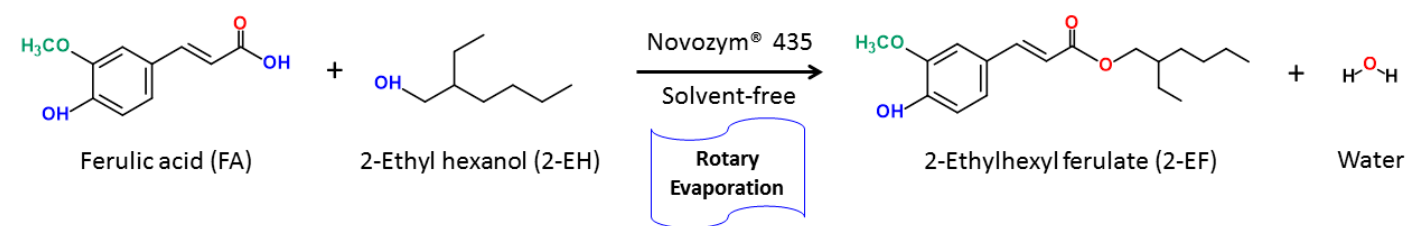

Scheme 1. Enzymatic synthesis of 2-ethylhexyl ferulate.

After incubation, liquid samples were withdrawn from the reaction mixture for analysis of 2-EF by high-performance liquid chromatography (HPLC). The sample was diluted with hexanol/ 2-methyl-2-butanol (1:150), and was injected (30 $\mathrm{L}$ ) into a HPLC (Hitachi L-7400; Tokyo, Japan) equipped with UV detector and Thermo C18 column $(250 \mathrm{~mm} \times 4.6 \mathrm{~mm}$, Agilent, Santa Clara, CA, USA). Separations were carried out by a gradient elution with $0.1 \%$ acetic acid and methanol, the flow rate was set to $1.0 \mathrm{~mL} / \mathrm{min}$, and 2-EF was detected under UV light at $325 \mathrm{~nm}$ as shown in Figure 7 . Calibration curves were prepared from the FA and 2-EF standards based on the peak areas. The molar conversion was defined as (mmol of 2 -EF production per mmol of initial FA) $\times 100 \%$.

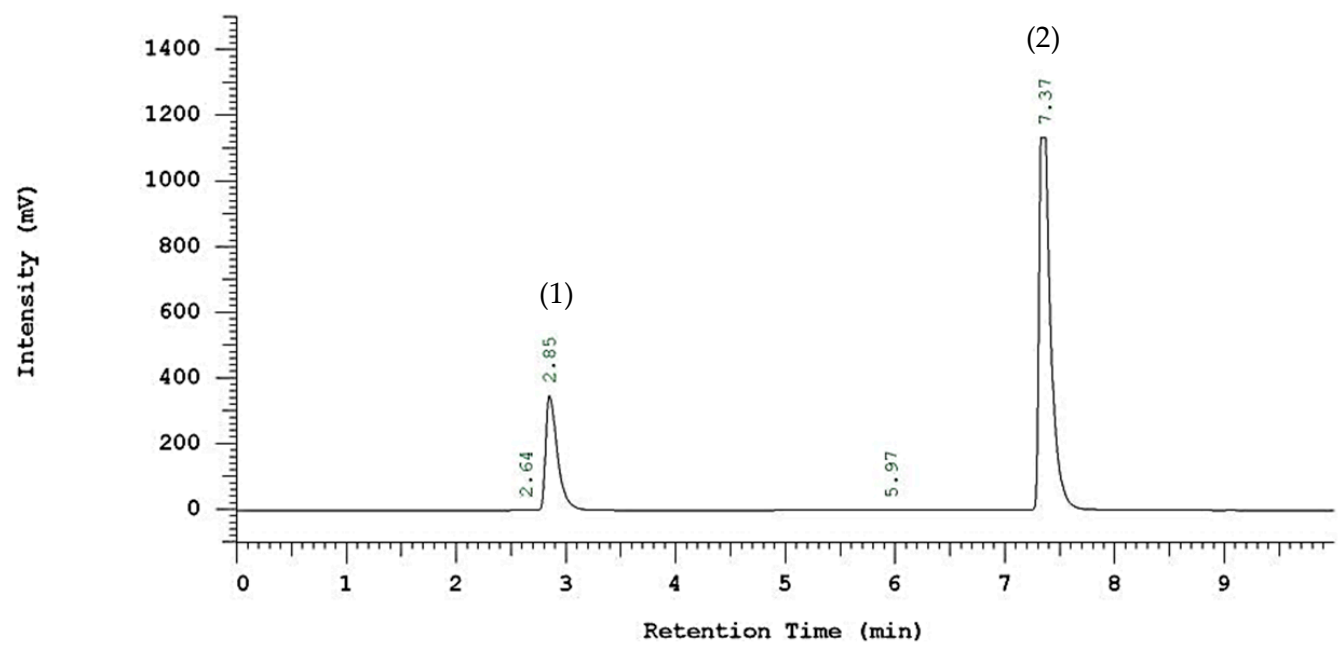

Figure 7. HPLC chromatogram of ferulic acid and its ester form. (1) ferulic acid; (2) 2-ethylhexyl ferulate. 


\subsection{Box-Behnken Design}

A Box-Behnken design for 15 experimental runs was employed in present study. To avoid bias, the 15 runs were performed in a totally random order. The variables and their levels selected for the study of 2-EF biosynthesis were: reaction temperature $\left(60^{\circ} \mathrm{C}-80^{\circ} \mathrm{C}\right)$, enzyme amount (500-1500 PLU) and reaction time (8-24 h), which were coded as shown in Table 5. Table 1 shows the independent factors (xi), levels and experimental design. Each experimental point was carried out in duplicate. Statistical parameters mentioned in present study including coefficient of determination $\left(R^{2}\right)$, root-mean-square error (RMSE), and absolute average deviation (AAD) were calculated by following Equations (1) to (3):

$$
R^{2}=1-\frac{\sum_{i=1}^{n}\left(Y_{p r e}-Y_{e x p}\right)^{2}}{\sum_{i=1}^{n}\left(Y_{m}-Y_{\exp }\right)^{2}}
$$

where $Y_{\text {pre }}$ is the predicted 2-EF yield (by either RSM or ANN), $Y_{\text {exp }}$ is the observed 2-EF yield and $Y_{m}$ is the average $2-\mathrm{EF}$ yield.

$$
R M S E=\sqrt{\frac{\sum_{i=1}^{n}\left(Y_{\text {pre }}-Y_{\text {exp }}\right)^{2}}{n}}
$$

where $Y_{\text {pre }}$ and $Y_{\text {exp }}$ are the predicted and experimental response, respectively, and $n$ is the number of experiments.

$$
A A D=\left[\frac{\sum_{i=1}^{n}\left(\left|Y_{\text {exp }}-Y_{\text {pre }}\right| / Y_{\text {pre }}\right)}{n}\right] \times 100
$$

where $Y_{\text {pre }}$ and $Y_{\exp }$ are the predicted and experimental response, respectively, and $n$ is the number of experiments.

Table 5. Coding of experimental parameters and related levels.

\begin{tabular}{ccccc}
\hline \multirow{2}{*}{ Parameters } & \multirow{2}{*}{ Symbol } & \multicolumn{3}{c}{ Coded Levels } \\
\cline { 3 - 5 } & & $-\mathbf{1}$ & $\mathbf{0}$ & $\mathbf{1}$ \\
\hline Reaction time $(\mathrm{h})$ & $\mathrm{X}_{1}$ & 8 & 16 & 24 \\
Enzyme amount $(\mathrm{PLU}){ }^{\mathrm{a}}$ & $\mathrm{X}_{2}$ & 500 & 1000 & 1500 \\
Reaction temperature $\left({ }^{\circ} \mathrm{C}\right)$ & $\mathrm{X}_{3}$ & 60 & 70 & 80 \\
\hline a PLU means propyl laurate units.
\end{tabular}

\section{Conclusions}

The present study demonstrates for the first time that immobilized $C$. antarctica lipase (Novozym ${ }^{\circledR} 435$ ) is able to synthesize 2-ethylhexyl ferulate (2-EF). A Box-Behnken design with RSM and ANN was selected to model and optimize the biocatalysis. Both RSM and ANN models for the 2-EF synthesis were built, and ANN was better than RSM in data fitting and prediction. The optimum synthesis condition modeled by ANN was in a reaction time of $24 \mathrm{~h}$, reaction temperature of $78^{\circ} \mathrm{C}$ and enzyme amount of 1485 PLU. The conversion of 2-EF under this optimum condition was verified to be $99.74 \%$. The reduced pressure evaporation system combined with solvent free reaction conditions can decrease the reaction time and reaction temperature for ferulic acid ester synthesis.

Acknowledgments: The authors are very grateful to the Ministry of Science and Technology of Taiwan, ROC for supporting this research (Grants No. MOST 104-2221-E-005-061-MY3 and MOST 104-2218-E-022-001-MY2).

Author Contributions: Yawo-Kuo Twu and Chwen-Jen Shieh conceived and designed the experiments; Kuo-Chuan Huang performed the experiments and analyzed the data; Kuo-Chuan Huang, Ying Li and Chwen-Jen Shieh wrote the paper. Jer-An Lin and Chia-Hung Kuo assisted paper revision.

Conflicts of Interest: The authors declare no conflict of interest. 


\section{References}

1. Liu, J.; Wen, X.Y.; Lu, J.F.; Kan, J.; Jin, C.H. Free radical mediated grafting of chitosan with caffeic and ferulic acids: Structures and antioxidant activity. Int. J. Biol. Macromol. 2014, 65, 97-106. [CrossRef] [PubMed]

2. Choo, W.S.; Birch, E.J. Radical scavenging activity of lipophilized products from lipase-catalyzed transesterification of triolein with cinnamic and ferulic acids. Lipids 2009, 44, 145-152. [CrossRef] [PubMed]

3. Itagaki, S.; Kurokawa, T.; Nakata, C.; Saito, Y.; Oikawa, S.; Kobayashi, M.; Hirano, T.; Iseki, K. In vitro and in vivo antioxidant properties of ferulic acid: A comparative study with other natural oxidation inhibitors. Food Chem. 2009, 114, 466-471. [CrossRef]

4. Mancuso, C.; Santangelo, R. Ferulic acid: Pharmacological and toxicological aspects. Food Chem. Toxicol. 2014, 65, 185-195. [CrossRef] [PubMed]

5. Guyot, B.; Bosquette, B.; Pina, M.; Graille, J. Esterification of phenolic acids from green coffee with an immobilized lipase from Candida antarctica in solvent-free medium. Biotechnol. Lett. 1997, 19, 529-532. [CrossRef]

6. Stamatis, H.; Sereti, V.; Kolisis, F.N. Studies on the enzymatic synthesis of lipophilic derivatives of natural antioxidants. J. Am. Oil Chem. Soc. 1999, 76, 1505-1510. [CrossRef]

7. Vosmann, K.; Weitkamp, P.; Weber, N. Solvent-free lipase-catalyzed preparation of long-chain alkyl phenylpropanoates and phenylpropyl alkanoates. J. Agric. Food Chem. 2006, 54, 2969-2976. [CrossRef] [PubMed]

8. Stamatis, H.; Sereti, V.; Kolisis, F.N. Enzymatic synthesis of hydrophilic and hydrophobic derivatives of natural phenolic acids in organic media. J. Mol. Catal. B Enzym. 2001, 11, 323-328. [CrossRef]

9. Chigorimbo-Murefu, N.T.L.; Riva, S.; Burton, S.G. Lipase-catalysed synthesis of esters of ferulic acid with natural compounds and evaluation of their antioxidant properties. J. Mol. Catal. B Enzym. 2009, 56, 277-282. [CrossRef]

10. Laszlo, J.A.; Compton, D.L. Enzymatic glycerolysis and transesterification of vegetable oil for enhanced production of feruloylated glycerols. J. Am. Oil Chem. Soc. 2006, 83, 765-770. [CrossRef]

11. Sun, S.; Shan, L.; Jin, Q.; Liu, Y.; Wang, X. Solvent-free synthesis of glyceryl ferulate using a commercial microbial lipase. Biotechnol. Lett. 2007, 29, 945-949. [CrossRef] [PubMed]

12. Nazare, A.C.; de Faria, C.M.; Chiari, B.G.; Petronio, M.S.; Regasini, L.O.; Silva, D.H.; Correa, M.A.; Isaac, V.L.; da Fonseca, L.M.; Ximenes, V.F. Ethyl ferulate, a component with anti-inflammatory properties for emulsion-based creams. Molecules 2014, 19, 8124-8139. [CrossRef] [PubMed]

13. Cunha, F.V.; Gomes, B.S.; Neto, B.S.; Ferreira, A.R.; de Sousa, D.P.; E Martins, M.D.; Oliveira, F.A. Ferulic acid ethyl ester diminished Complete Freund's Adjuvant-induced incapacitation through antioxidant and anti-inflammatory activity. Naunyn Schmiedebergs Arch. Pharmacol. 2015, 389, 117-130. [CrossRef] [PubMed]

14. Machado, K.C.; Oliveira, G.L.; Machado, K.C.; Islam, M.T.; Junior, A.L.; de Sousa, D.P.; Freitas, R.M. Anticonvulsant and behavioral effects observed in mice following treatment with an ester derivative of ferulic acid: Isopentyl ferulate. Chem. Biol. Interact. 2015, 242, 273-279. [CrossRef] [PubMed]

15. Shirai, A.; Kajiura, M.; Omasa, T. Synergistic photobactericidal activity based on ultraviolet-A irradiation and ferulic acid derivatives. Photochem. Photobiol. 2015, 91, 1422-1428. [CrossRef] [PubMed]

16. Yang, X.Z.; Diao, X.J.; Yang, W.H.; Li, F.; He, G.W.; Gong, G.Q.; Xu, Y.G. Design, synthesis and antithrombotic evaluation of novel dabigatran prodrugs containing methyl ferulate. Bioorg. Med. Chem. Lett. 2013, 23, 2089-2092. [CrossRef] [PubMed]

17. Tsai, Y.C.; Lee, Y.M.; Hsu, C.H.; Leu, S.Y.; Chiang, H.Y.; Yen, M.H.; Cheng, P.Y. The effect of ferulic acid ethyl ester on leptin-induced proliferation and migration of aortic smooth muscle cells. Exp. Mol. Med. 2015, 47, e180. [CrossRef] [PubMed]

18. Kikuzaki, H.; Hisamoto, M.; Hirose, K.; Akiyama, K.; Taniguchi, H. Antioxidant properties of ferulic acid and its related compounds. J. Agric. Food Chem. 2002, 50, 2161-2168. [CrossRef] [PubMed]

19. Giuliani, S.; Piana, C.; Setti, L.; Hochkoeppler, A.; Pifferi, P.G.; Williamson, G.; Faulds, C.B. Synthesis of pentylferulate by a feruloyl esterase from Aspergillus niger using water-in-oil microemulsions. Biotechnol. Lett. 2001, 23, 325-330. [CrossRef]

20. Sun, S.; Song, F.; Bi, Y.; Yang, G.; Liu, W. Solvent-free enzymatic transesterification of ethyl ferulate and monostearin: Optimized by response surface methodology. J. Biotechnol. 2012, 164, 340-345. [CrossRef] [PubMed] 
21. Yoshida, Y.; Kimura, Y.; Kadota, M.; Tsuno, T.; Adachi, S. Continuous synthesis of alkyl ferulate by immobilized Candida antarctica lipase at high temperature. Biotechnol. Lett. 2006, 28, 1471-1474. [CrossRef] [PubMed]

22. Compton, D.L.; Laszlo, J.A.; Berhow, M.A. Lipase-catalyzed synthesis of ferulate esters. J. Am. Oil Chem. Soc. 2000, 77, 513-519. [CrossRef]

23. Sun, S.; Zhu, S.; Bi, Y. Solvent-free enzymatic synthesis of feruloylated structured lipids by the transesterification of ethyl ferulate with castor oil. Food Chem. 2014, 158, 292-295. [CrossRef] [PubMed]

24. Guo, T.; Su, D.; Huang, Y.; Wang, Y.; Li, Y.H. Ultrasound-assisted aqueous two-phase system for extraction and enrichment of Zanthoxylum armatum lignans. Molecules 2015, 20, 15273-15286. [CrossRef] [PubMed]

25. Rafigh, S.M.; Yazdi, A.V.; Vossoughi, M.; Safekordi, A.A.; Ardjmand, M. Optimization of culture medium and modeling of curdlan production from Paenibacillus polymyxa by RSM and ANN. Int. J. Biol. Macromol. 2014, 70, 463-473. [CrossRef] [PubMed]

26. Maran, J.P.; Priya, B. Comparison of response surface methodology and artificial neural network approach towards efficient ultrasound-assisted biodiesel production from muskmelon oil. Ultrason. Sonochem. 2015, 23, 192-200. [CrossRef] [PubMed]

27. Huang, K.C.; Li, Y.; Twu, Y.K.; Shieh, C.J. High efficient synthesis of enzymatic 2-ethylhexyl ferulate at solvent-free and reduced pressure evaporation system. J. Mater. Sci. Chem. Eng. 2015, 3, 33-40. [CrossRef]

28. Tao, Y.; Wu, D.; Zhang, Q.A.; Sun, D.W. Ultrasound-assisted extraction of phenolics from wine lees: Modeling, optimization and stability of extracts during storage. Ultrason. Sonochem. 2014, 21, 706-715. [CrossRef] [PubMed]

Sample Availability: Samples of 2-ethylhexyl ferulate are available from the authors.

(C) 2016 by the authors; licensee MDPI, Basel, Switzerland. This article is an open access article distributed under the terms and conditions of the Creative Commons Attribution (CC-BY) license (http://creativecommons.org/licenses/by/4.0/). 